\title{
Electrochemical Reduction of Carbon Dioxide at Surface Oxidized Copper Electrodes
}

\author{
G. Keerthiga, B. Viswanathan, C. Alex Pulikottil and Raghuram Chetty
}

\begin{abstract}
Carbon dioxide a common greenhouse gas is converted to value added products such as methane and ethane by electrochemical reduction at a surface oxidized copper electrode. The product yield and the relationships between the surface chemistry and reaction behavior were investigated. Ethane was observed as a dominant product at the surface oxidized $\mathrm{Cu}$ electrodes suggesting that $\mathrm{Cu}$ (I) species play a critical role in selectivity towards $C 2$ species.
\end{abstract}

Keywords--- Carbon Dioxide, Copper, Electrochemical Reduction, Ethane

\section{INTRODUCTION}

$\mathrm{C}$ ARBON DIOXIDE $\left(\mathrm{CO}_{2}\right)$ represents a prospective source of $\mathrm{C} 1$ feedstock for the production of chemicals and fuels in view of the vastness of its supply. As of current estimation, $\mathrm{CO}_{2}$ is present in the atmosphere with a volumetric concentration of $0.0391 \%$ (391 ppmv) [1]. The ways and means by which carbon dioxide can be utilized are as follows: (1) as a non toxic feedstock which is used to replace harmful chemicals, (2) raw material for the production of some polymers, (3) as an alternate and efficient feed stock, and (4) production of new chemicals which could positively impact carbon balance [2]. The electrochemical reduction process utilizes only gaseous carbon dioxide and possibly protons from aqueous electrolytes and yields a variety of hydrocarbon products. The activation of carbon dioxide and its subsequent conversion to fuels and chemicals can be achieved by a number of methods such as chemical, thermo-chemical, photochemical, photoelectron chemical, biochemical, bio-photoelectrochemical and electrochemical routes [3]. All these routes were employed individually for the reduction, but generally combined with each other to increase its efficiency. The electrochemical method is considered as an attractive technique due to the simplicity and ambient operation conditions. The objective of this study is to analyze the products formed by the electroreduction of $\mathrm{CO}_{2}$ on a $\mathrm{Cu}$ electrode which is oxidized at high temperature and to optimize suitable conditions for maximizing the desired product.

G. Keerthiga, Research Scholar, Chemical Engineering Department, Indian Institute of Technology Madras, Chennai. keerthigagopal@gmail.com.

B. Viswanathan, Professor, National Centre for Catalysis Research, Indian Institute of Technology Madras, Chennai.bvnathan@iitm.ac.in.

C. Alex Pulikottil, $R \&$ D Centre, Indian Oil Corporation Limited (IOCL), Faridabad, Delhi.pulikottilac@iocl.co.in.

Raghuram Chetty, Assistant Professor, Chemical Engineering Department, Indian Institute of Technology Madras, Chennai, India. raghuc@iitm.ac.in..

\section{EXPERIMENTAL DETAILS}

The metal electrodes used in the present study are pure $\mathrm{Cu}$ sheet of $4 \mathrm{~cm}^{2}$ where electrical connection is established through the same strip. The $\mathrm{Cu}$ strips were polished with fine emery paper and electrolytically treated in $1 \mathrm{~mol} \mathrm{dm}^{-3}$ phosphoric acid [4] and sulphuric acid, cleaned with acetone to remove grease, washed subsequently with water and used as working electrode. The same $\mathrm{Cu}$ electrodes were modified by exposing them to high temperature oxygen mixed LPG gas at a flame temperature of $900{ }^{\circ} \mathrm{C}$, referring as surface oxidized $\mathrm{Cu}$ electrode. X-ray diffraction (XRD) was recorded before and after electrode modification. The electrochemical measurements were conducted with an EC epsilon potentiostat. The experiments were performed in a laboratorymade $\mathrm{H}$-cell with $\mathrm{Ag} / \mathrm{AgCl}$ saturated $\mathrm{KCl}$ as reference electrode. Platinum foil was used as the counter electrode while the supporting electrolyte was $0.5 \mathrm{~mol} \mathrm{dm}^{-3} \mathrm{KCl}$. The supporting electrolyte was purged with $\mathrm{CO}_{2}$ gas for $1 \mathrm{hr}$, and the $\mathrm{CO}_{2}$-saturated solution was reduced electrolytically at cathodic polarizations in the range determined from cyclic voltammogram. Gaseous products obtained during the electro reduction were analysed for every one hour by Gas Chromatography (GC) for the presence of hydrocarbons by Porapak Q column through Flame ionization detector with $\mathrm{N}_{2}$ as carrier.

\section{RESULTS AND DISCUSSION}

\section{A. Voltammogram}

Figure 1 shows the XRD pattern of $\mathrm{Cu}$ before and after oxidization, in which reflections corresponding to $\mathrm{Cu}$ and $\mathrm{Cu}_{2} \mathrm{O}$ was observed indicating that the composition of pure $\mathrm{Cu}$ has been oxidized by the high temperature heat treatment.

Cyclic voltammograms (CVs) were performed at room temperature at the surface oxidized $\mathrm{Cu}$ electrode in $\mathrm{KCl}$ electrolyte to determine the reduction potential. Figure 2 shows the current-potential curves obtained with the oxidized $\mathrm{Cu}$ electrode in $\mathrm{CO}_{2}$ saturated and $\mathrm{N}_{2}$ saturated (blank) $\mathrm{KCl}$ solution. The reduction peak at potential greater than $-0.9 \mathrm{~V}$ for the $\mathrm{CO}_{2}$ saturated solution in comparision with that of nitrogen saturated solution signifies the reduction of $\mathrm{CO}_{2}$. The steep peak at $-0.2 \mathrm{~V}$ could be due to the adsorption of $\mathrm{Cl}^{-}$ions on the electrode surface [5]. 


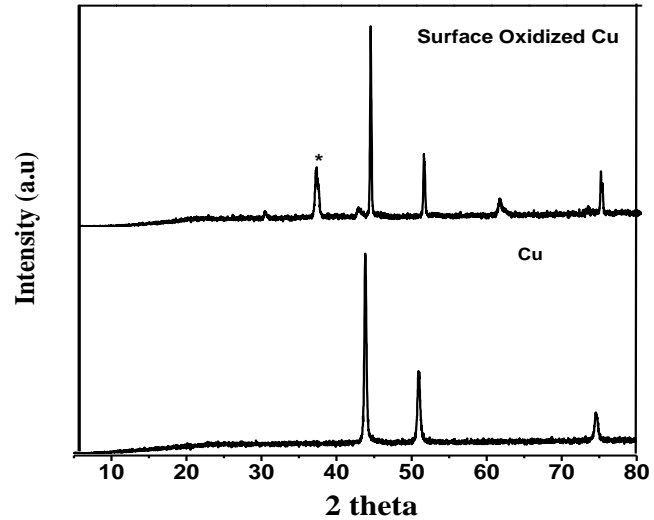

Figure 1: XRD Pattern of Surface Oxidized Copper and Copper

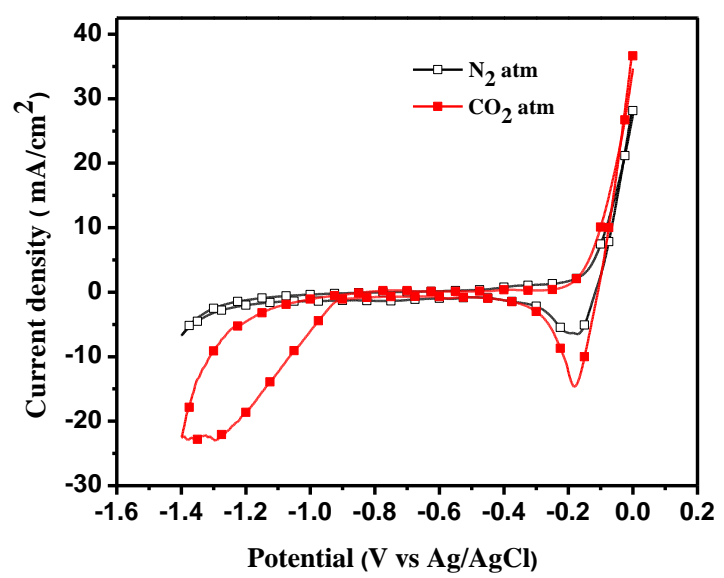

Figure 2: Cyclic Voltammogram of $\mathrm{CO}_{2}$ Reduction on Surface Oxidized $\mathrm{Cu}$ Electrode in $1 \mathrm{~mol} \mathrm{dm}^{-3} \mathrm{KCl}$ at Room Temperature at a Scan Rate of $10 \mathrm{mV} \mathrm{s}^{-1}$.

\section{B. Electroreduction of $\mathrm{CO}_{2}$}

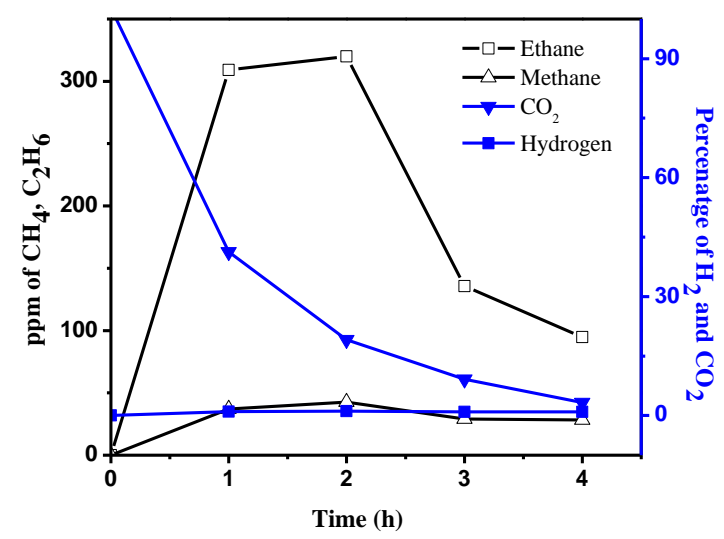

Figure 3: Effect of Time on ppm/Percentage of Products formed by Electroreduction of $\mathrm{CO} 2$ with Surface Oxidized

$\mathrm{Cu}$ as Working Electrode in $0.5 \mathrm{~mol} \mathrm{dm}^{-3} \mathrm{KCl}$ at Room

Temperatue at a Potential of $-1.4 \mathrm{~V}$ vs $\mathrm{Ag} / \mathrm{AgCl}$.

From the increase in reduction current seen in $\mathrm{CV}$ studies at potentials greater than $-0.9 \mathrm{~V}$ for the $\mathrm{CO}_{2}$ saturated $\mathrm{KCl}$ solution, five different potentials were chosen in the range from -0.9 to $-2 \mathrm{~V}$ for electrolysis and the products were analyzed by GC. The reduction of $\mathrm{CO}_{2}$ saturated solution was carried at the desired potential for about 4 hours. As can be seen from figure 3, maximum products formation was observed within the first 2 hours, which may be due to scarcity of $\mathrm{CO}_{2}$ in the system at longer time and could also be due to the deposition of poisoning species on electrode surafce [6].

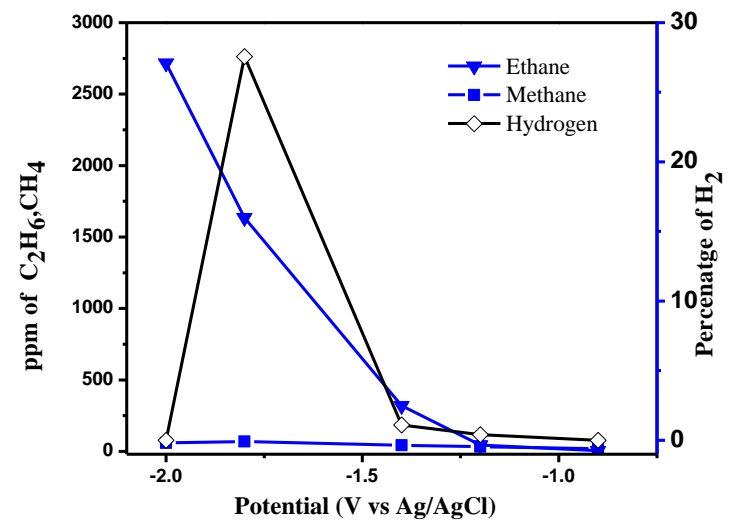

Figure 4: Effect of Potential for the ppm of Products formed by the Electrochemical Reduction of $\mathrm{CO}_{2}$ on Surface Oxidized $\mathrm{Cu}$ Electrode in $0.5 \mathrm{~mol} \mathrm{dm}^{-3} \mathrm{KCl}$ at Room Temperature.

Figure 3 illustrates methane and ethane to be the major products formed during reduction, while hydrogen is evolved as a byproduct. Among the five different potential chosen for $\mathrm{KCl}$ medium, $-2 \mathrm{~V}$ showed the highest ethane evolution near to $2700 \mathrm{ppm}$, with least hydrogen evolution as shown in figure 4 .

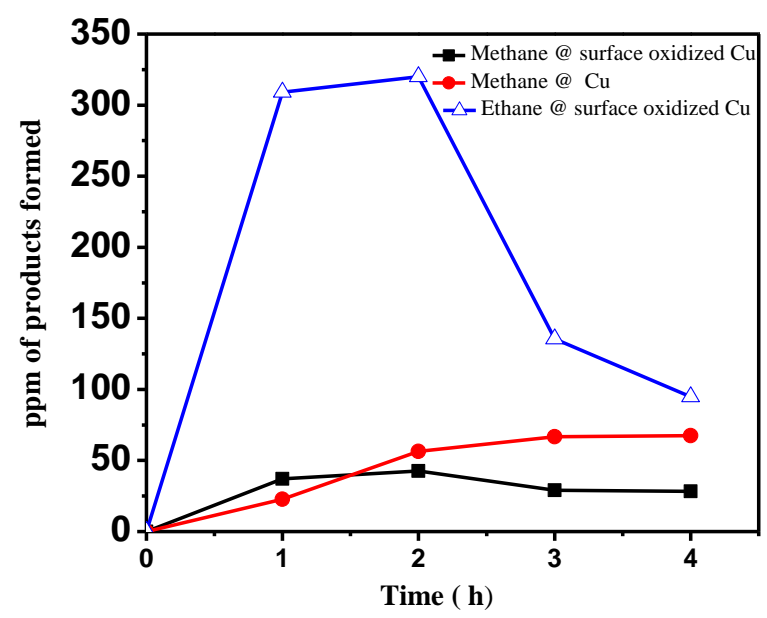

Figure 5: Comparison of Products formed by Electroreduction of $\mathrm{CO} 2$ with Surface Oxidized $\mathrm{Cu}$ and Unmodified $\mathrm{Cu}$

Electrode in $0.5 \mathrm{~mol} \mathrm{dm}^{-3} \mathrm{KCl}$ at Room Temperatue at a Potential of $-1.4 \mathrm{~V}$ vs $\mathrm{Ag} / \mathrm{AgCl}$.

Figure 5 compares the products formed by electroreduction of $\mathrm{CO}_{2}$ with surface oxidized $\mathrm{Cu}$ and unmodified $\mathrm{Cu}$ electrode in $0.5 \mathrm{~mol} \mathrm{dm}{ }^{-3} \mathrm{KCl}$ at a potential of $-1.4 \mathrm{~V} \mathrm{vs} \mathrm{Ag} / \mathrm{AgCl}$. At the similar potential, ethane is formed 
on the surface oxidized $\mathrm{Cu}$ electrode but not on the unmodified $\mathrm{Cu}$ electrode. The reason for enhancement of $\mathrm{C} 2$ products on the copper electrode is not clear and requires further investigation. Methane and hydrogen evolution is nearly the same for both the electrodes during the initial period of reduction.

\section{CONCLUSION AND FUTURE ENHANCEMENT}

The electro reduction of $\mathrm{CO}_{2}$ was performed with surface oxidized $\mathrm{Cu}$ and unmodified $\mathrm{Cu}$ electrode in $\mathrm{KCl}$ electrolyte and the products were analyzed using gas chromatography. The reduction performed over a range of potentials showed C2 hydrocarbon as the major product formed on the surface oxidized $\mathrm{Cu}$ electrode whose evolution is higher when compared with $\mathrm{Cu}$ electrodes.

\section{ACKNOWLEDGMENT}

We would like to thank Indian Oil Corporation Limited (IOCL), R\&D centre, Faridabad for the fellowship and Department of Science and Technology (DST) for funding National Centre for Catalysis Research (NCCR).

\section{REFERENCES}

[1] C. Song, "Global challenges and strategies for control, conversion and utilization of $\mathrm{CO}_{2}$ for sustainable development involving energy, catalysis,adsorption and chemical processing", Catal Today, Vol. 115, Pp. 2-32, 2006.

[2] B.Viswanathan, "Reflections on the electrochemical reduction of carbon dioxide on metallic surfaces", Indian J Chem, Sec A, Vol 51, Pp. 166-174, 2011.

[3] M.A Scibioh and B.Viswanathan, "Electrochemical reduction of carbon dioxide: A status report" Proc. Indn. Natl. Acad. Sci, Vol.70A, Pp. 1-56, 2004.

[4] H. Shibata, Jacob A. Moulijn,G. Mul, "Enabling Electrocatalytic Fischer-Tropsch Synthesis from Carbon Dioxide Over Copper-based Electrodes " Catal Lett, Vol 123, Pp. 186-192, 2008.

[5] K. Ogura, R. Ferrell, V. Cuginic, S. Smotkin, S. Villalpando, " $\mathrm{CO}_{2}$ attraction by specifically adsorbed anions and subsequent accelerated electrochemical reduction", Electrochim Acta, Vol.56, Pp.381-386,2010.

[6] J. Yano, T. Morita, K. Shimano, Y. Nagami, S.Yamasaki, "Selective ethylene formation by pulse-mode electrochemical reduction of carbon dioxide using copper and copper oxide electrodes", J Solid State Electrochem, Vol.11, Pp. 554-557, 2007. 